\title{
Genetic Differentiation at Microsatellite Loci Among Populations of Mycosphaerella graminicola from California, Indiana, Kansas, and North Dakota
}

\author{
Suraj Gurung, Stephen B. Goodwin, Mehdi Kabbage, William W. Bockus, and Tika B. Adhikari
}

First and fifth authors: Department of Plant Pathology, North Dakota State University, NDSU Department 7660, P.O. Box 6050, Fargo, ND 58108-6050; second author: United States Department of Agriculture-Agricultural Research Service, 915 West State Street, Department of Botany and Plant Pathology, Purdue University, West Lafayette, IN 47907-2054; third author: Department of Plant Pathology and Microbiology, Texas A\&M University, College Station, TX 77843-2132; and fourth author: Department of Plant Pathology, Kansas State University, 4024 Throckmorton Plant Science Center, Manhattan, KS 66506-5502.

Current address of the first author: Department of Plant Pathology, University of California, Davis, c/o U.S. Agricultural Research Station, 1636 E. Alisal Street, Salinas, CA 93905.

Accepted for publication 10 June 2011.

\begin{abstract}
Gurung, S., Goodwin, S. B., Kabbage, M., Bockus, W. W., and Adhikari, T. B. 2011. Genetic differentiation at microsatellite loci among populations of Mycosphaerella graminicola from California, Indiana, Kansas, and North Dakota. Phytopathology 101:1251-1259.

Mycosphaerella graminicola causes Septoria tritici blotch (STB) in wheat (Triticum aestivum) and is considered one of the most devastating pathogens of that crop in the United States. Although the genetic structures of $M$. graminicola populations from different countries have been analyzed using various molecular markers, relatively little is known about $M$. graminicola populations from geographically distinct areas of the United States and, in particular, of those from spring versus winter wheat. These are exposed to great differences in environmental conditions, length and season of host-free periods, and resistance sources used in geographically separated wheat breeding programs. Thus, there is more likely to be genetic differentiation between populations from spring versus winter wheat than there is among those within each region. To test this hypothesis, 330 single-spore isolates of $M$. graminicola representing 11 populations ( 1 from facultative winter wheat in California, 2 from spring wheat in North Dakota, and 8 from winter wheat in Indiana and

mating types in the populations from Kansas, Indiana, and North Dakota, but a deviation from a 1:1 ratio in the California population. In total, 306 haplotypes were detected, almost all of which were unique in all 11 populations. High levels of gene diversity $(H=0.31$ to 0.56$)$ were observed within the 11 populations. Significant $(P \leq 0.05)$ gametic disequilibrium, as measured by the index of association ( $r$ BarD), was observed in California, one Indiana population (IN1), and three populations (KS1, $\mathrm{KS} 2$, and KS3) in Kansas that could not be explained by linkage. Corrected standardized fixation index $\left(G^{\prime \prime}{ }_{S T}\right)$ values were 0.000 to 0.621 between the 11 populations and the majority of pairwise comparisons were statistically significant $(P \leq 0.001)$, suggesting some differentiation between populations. Analysis of molecular variance showed that there was a small but statistically significant level of genetic differentiation between populations from spring versus winter wheat. However, most of the total genetic variation ( $>98 \%$ ) occurred within spring and winter wheat regions while $<2 \%$ was due to genetic differentiation between these regions. Taken together, these results provide evidence that sexual recombination occurs frequently in the $M$. graminicola populations sampled and that most populations are genetically differentiated over the major spring- and winter-wheat-growing regions of the United States.
\end{abstract} Kansas) were analyzed for mating type frequency and for genetic variation at 17 microsatellite or simple-sequence repeat (SSR) loci. Analysis of clone-corrected data revealed an equal distribution of both
Additional keywords: genetic diversity.
Mycosphaerella graminicola (Fuckel) J. Schrot. (anamorph: Septoria tritici (Desm.) causes Septoria tritici blotch (STB) on wheat (Triticum aestivum L.) worldwide $(16,23,26)$. The disease can reduce both quality and quantity of wheat, and yield losses of $\leq 40 \%$ have been reported in areas with relatively high rainfall and moderate temperatures (14). After the late 1960s, there was rapid replacement of local wheat cultivars with semidwarf, early-maturing, and high-yielding cultivars. These changes in wheat cultivars and agricultural systems, along with movement of infected seed and development of fungicide resistance, increased the incidence of STB from a minor problem to economically significant levels $(4,14,15)$.

For many fungi, sexual recombination occurs infrequently or may be absent; however, in the case of M. graminicola, sexual

Corresponding author: T. B. Adhikari; E-mail addresses: tika.adhikari@ndsu.edu or tadhikari31@yahoo.com

doi:10.1094/PHYTO-08-10-0212

(c) 2011 The American Phytopathological Society recombination is frequent, with one to two or multiple cycles of sexual reproduction $(9,10)$ occurring during the growing season. Sexual spores (ascospores) are produced in pseudothecia (ascocarps) and act as primary sources of inoculum for the initiation of STB epidemics during the crop-growing season (40). Previous studies indicated that the windborne ascospores can travel $\leq 100$ $\mathrm{km}$ (26) to cause high densities of infection. For example, Zhan et al. (50) reported that Oregon wheat fields had at least 70 primary ascospore infections per square meter. In contrast to sexual reproduction, clonal propagation occurs via rain-splash of asexual spores (pycnidiospores) that usually are dispersed over short distances $(8,26)$. Therefore, asexual reproduction of $M$. graminicola can generate clones that are geographically separated, usually by a few meters at most (5).

Different molecular markers such as mating-type genes $(44,47)$, random amplified polymorphic DNA (RAPD) (37), restriction fragment length polymorphism (RFLP) (26), amplified fragment length polymorphism (AFLP) $(21,38)$, and microsatellites (7) have been used to analyze the genetic structure of $M$. graminicola populations at local, regional, and continental scales. M. gramini- 
cola is a heterothallic fungus, and both the MAT1-1 and MAT1-2 mating-type idiomorphs have been characterized (44). Analyses of numerous $M$. graminicola populations from many geographical locations worldwide revealed an equal frequency of both mating types, except for only four samples from Oregon, Switzerland, and Syria $(44,47)$. The rare exceptions probably resulted from small sample sizes or were thought to represent type II errors due to the large numbers of samples analyzed $(44,47)$.

Molecular variability has been very high in all populations sampled worldwide, regardless of marker type analyzed. For example, a high level of genetic variability was detected in populations of M. graminicola collected from Saskatchewan, western Canada (37) and from Germany (38) using RAPD and AFLP markers, respectively. Linde et al. (26) used RFLP markers to analyze $M$. graminicola populations from Israel, Switzerland, and the United States and discovered that the genetic structures across wide geographical areas were similar. In another study, McDonald and Martinez (28) found a high level of RFLP variability within a population collected from a single field in California.

Some of the previous investigations reported a high level of genetic diversity within populations but little genetic differentiation among populations of $M$. graminicola $(26,38,51)$. Although these studies provided excellent insights into the genetic structure of $M$. graminicola populations globally, they did not always sample populations with the greatest likelihood of showing differentiation, and included relatively few samples from North America. Wheat in the United States is divided into several market classes based on hardness, seed color, and adaptation. Production of each class is restricted geographically and their genetic backgrounds can be very different. Due to these differences, each market class of wheat could have its own population of $M$. graminicola that is specifically adapted to the differing genetic backgrounds or the regional environmental conditions under which it is grown. For example, North Dakota has growing conditions from May to August that are suited for the production of hard, red spring wheat, whereas Kansas and Indiana produce primarily hard and soft red winter wheat, respectively. In the mild climate of California, spring wheat or facultative winter types are planted in the fall and harvested during May or June. Wheat in North Dakota is planted in the spring and harvested during late summer or early fall, while the winter wheat cultivars grown in Kansas and Indiana are planted in the fall, remain dormant during the winter, and are harvested during June or July. Populations of $M$. graminicola infecting spring wheat survive an 8-month hostfree period of extremely cold winter weather in infected crop residues from harvest until spring, whereas those on winter wheat survive a much shorter host-free period of hot, often dry weather during summer and early fall.

The DNA marker systems used to analyze the genetic structure of $M$. graminicola populations over the past decade have technical or operational limitations which can be overcome by microsatellite or simple-sequence repeat (SSR) markers (39). SSR loci tend to be highly polymorphic and are easy to score compared with other, more time-consuming amplifiable markers (39). Recently, numerous SSR loci have been characterized and genetically mapped in the genome of $M$. graminicola (17), and can be used to estimate the genetic diversity within and between populations from spring (California and North Dakota) and winter (Indiana and Kansas) cultivars of wheat.

In this study, our primary goal was to test the hypothesis that the geographically and potentially ecologically separated populations of M. graminicola from different market classes of wheat in the United States would be genetically differentiated. Knowledge of the genetic structure of $M$. graminicola populations in each wheat-producing region and of genetic exchange among regions could help guide the development of new wheat cultivars in breeding programs (37) and also could help to extend the effectiveness of control measures such as fungicide applications and resistant cultivars (29). Because sexual recombination can facilitate the rapid dissemination of introduced alleles throughout a population and has been found in other populations of this fungus, a secondary goal was to estimate the frequencies of the matingtype idiomorphs and disequilibrium among loci in M. graminicola populations from spring and winter wheat to test the hypothesis that these populations undergo regular cycles of sexual reproduction.

\section{MATERIALS AND METHODS}

Sampling, isolation, and description of the fungal populations. Leaf samples showing typical symptoms of STB were collected randomly from commercial fields in the four wheat-producing states of California, Indiana, Kansas, and North Dakota. Detailed information regarding the sampling methods, sources, and isolation techniques for the isolates from Kansas and California were provided previously $(21,22)$. A subset of isolates $(n=$ 121) was randomly selected from the previously studied Kansas populations $(21,22)$ whereas all California isolates were included in this study.

For the California population, isolates were collected from a single field of the experimental spring wheat line D6301 (highly susceptible to STB) in Colusa County during 2004 and was considered as one population (CA population, $n=66$ ). The Kansas populations were collected from hard red winter wheat (unknown cultivars) during the 2003-04 growing season, and six populations were divided according to sampling sites and inoculation methods used. Three of the Kansas populations represented the south, central, and north regions of the state. The south population (KS1; $n=26$ ) was collected from Pratt, Harvey, Stafford, Reno, Crawford, Meade and Stanton Counties; the central population (KS2; $n=15$ ) had isolates from Dickinson, Barton, Ellis, Rush, and Marion Counties; and the north population (KS3; $n=$ 22) was from Cloud, Mitchell, Rooks, Clay, Jewell, Osborne, Pottawatomie, and Riley Counties. The remaining three populations from Kansas were the field population (KS4, $n=18)$, the natural inoculum population $(\mathrm{KS} 5, n=20)$, and the microplot population (KS6, $n=20$ ) from Ellis (central), Cloud (north) and Marion (central) Counties, respectively (22).

In North Dakota, the ND1 population $(n=24)$ was collected from Cavalier County near Langdon from spring wheat (unknown cultivars) during 2004 and isolated by Shaukat Ali. The ND2 population $(n=41)$ was collected by Dave Long (United States Department of Agriculture-Agricultural Research Service, Cereal Disease Laboratory, St. Paul, MN) during 1995 near the cities of Langdon, Minot and Harvey in Cavalier, Ward and Wells Counties from spring wheat (unknown cultivars), and was isolated by Guodong Zhang. Two Indiana populations were collected from experimental fields of winter wheat in the Agronomy Center for Research and Education farm, West Lafayette, IN, during 2009. The IN1 population $(n=35)$ was collected from winter wheat 'Monon' (susceptible to STB) and the IN2 population $(n=43)$ was sampled from an unknown wheat cultivar.

The isolates collected from each state were combined into regional populations representing California $(n=66)$, Indiana $(n=78)$, Kansas $(n=121)$, and North Dakota $(n=65)$ (Table 1$)$. Individual populations of $M$. graminicola collected from different locations within the four states were considered subpopulations collectively representing the California environment, Indiana environment, Kansas environment, and North Dakota environment. The isolates collected from spring wheat cultivars in California and North Dakota together were regarded as a spring wheat population while those sampled from cultivars of winter wheat in Indiana and Kansas were combined into a winter wheat population. Similarly, all isolates collected from spring and winter wheat in the four states were combined and considered the total population sample. 
To isolate the fungus, leaf samples were cut into 2-cm-long pieces and 10 leaf pieces per sampling site were placed in a $9-\mathrm{cm}-$ diameter plastic petri dish containing wet filter paper. The plates were kept at room temperature $\left(20\right.$ to $\left.25^{\circ} \mathrm{C}\right)$ for $24 \mathrm{~h}$ to allow cirrhi to ooze out from pycnidia. A sterile glass needle was used to transfer one cirrhus from a single pycnidium per lesion to a petri dish containing one-fourth-strength Difco potato dextrose agar (PDA) (10 $\mathrm{g}$ of Difco potato dextrose agar and $15 \mathrm{~g}$ of agar in 1 liter of water). Each cirrhus was streaked over the surface of a PDA plate to separate individual spores. PDA plates containing spores were incubated at room temperature for 2 days. Isolated colonies originating from a single spore were transferred separately to a flask containing liquid yeast glucose (YG) medium ( $2 \%$ glucose and $0.5 \%$ yeast extract), and the flask was placed on an orbital shaker $(180 \mathrm{rpm})$ incubated at $20^{\circ} \mathrm{C}$ for 5 to 10 days. Liquid cultures were centrifuged for 8 to $10 \mathrm{~min}$ at $1,300 \mathrm{rpm}$ to concentrate the spores and mycelia and were stored at $-80^{\circ} \mathrm{C}$.

DNA isolation and quantification. DNA was extracted from freeze-dried fungal cultures using a cetyltrimethylammonium bromide (CTAB) protocol as described by Murray and Thompson (33) and modified by Kerényi et al. (24). In all, $\approx 100 \mu \mathrm{l}$ of $1 \times$ Tris-EDTA (10 mM Tris and $1 \mathrm{mM}$ EDTA, pH 8.0) buffer was added to each DNA sample before storage at $-20^{\circ} \mathrm{C}$. A spectrophotometer (ND-1000; NanoDrop Technologies, Wilmington, DE) was used to quantify the nucleic acids and working solutions of DNA at $10 \mathrm{ng} / \mu \mathrm{l}$ were prepared from each sample for all polymerase chain reaction (PCR) analyses.

Mating type determination. Distribution of mating-type alleles in each population was determined by multiplex PCR as described previously (44). The primer sequences $5^{\prime}$-CCGCTT TCTGGCTTCTTCGCACTG-3' (forward) and 5'-TGGACACC ATGGTGAGAGAACCT-3' (reverse) amplified a 340-bp fragment from MAT1-1 isolates, and the primer sequences 5'-GGC GCCTCCGAAGCAACT-3' (forward) and 5'-GATGCGGTTCTG GACTGGAG-3' (reverse) amplified a 660-bp fragment from MAT1-2 isolates. Primers were synthesized by Integrated DNA Technologies (IDT) Inc. (Coralville, IA) and all PCR reagents were purchased from the Promega Corporation (Madison, WI). PCR mixtures with $2 \mu \mathrm{l}$ of sterile distilled water without a DNA template or a combination of primer solutions and sterile water were used as negative controls. All PCRs were carried out in a programmed PTC-100 Peltier Thermal Cycler (MJ Research, Inc., Waterman, MA). Each PCR reaction had 30 cycles of the following thermal profile: $1 \mathrm{~min}$ at $94^{\circ} \mathrm{C}$ for initial denaturation, $30 \mathrm{~s}$ at $68^{\circ} \mathrm{C}$ for annealing, $1 \mathrm{~min}$ at $72^{\circ} \mathrm{C}$ for extension, followed by a final 10 -min extension at $72^{\circ} \mathrm{C}$. To confirm the results, each PCR reaction was run twice. PCR-amplified products were separated in $1 \%(\mathrm{wt} / \mathrm{vol})$ agarose gels in $0.5 \times$ Tris-borate-EDTA (TBE) buffer (0.089 M Tris, $0.089 \mathrm{M}$ boric acid, and $0.002 \mathrm{M}$
EDTA). Gels were run for $90 \mathrm{~min}$ at $115 \mathrm{~V}$ and stained with ethidium bromide $(10 \mathrm{mg} / \mathrm{ml})$ for $15 \mathrm{~min}$. Each gel was photographed with a Fluorochem 2200 Image system (Alpha Innotech Corp., San Leandro, CA). A 100-bp DNA ladder (Invitrogen Corporation, Carlsbad, CA) was used as a size marker on each gel.

Haplotype identification. Primers for 23 previously characterized SSR loci (17) were tested for polymorphism using four DNA samples of $M$. graminicola from spring and winter wheat. Primers for two SSR loci did not produce polymorphic bands. Four SSR loci had bands but also showed nonspecific amplification, while the rest produced larger, specific, and reproducible bands. On the basis of this initial test, 17 SSR loci were selected and used to analyze the genetic structure of $M$. graminicola populations from spring or winter wheat in California, Indiana, Kansas, and North Dakota. Primers were synthesized by IDT Inc. and all PCR reagents were purchased from the Promega Corporation. Each PCR reaction $(10 \mu \mathrm{l})$ contained $3 \mu \mathrm{l}$ of sterile deionized water, $1 \mu \mathrm{l}$ of genomic DNA at $10 \mathrm{ng} / \mu \mathrm{l}, 2 \mu \mathrm{l}$ of $5 \times$ Taq polymerase buffer, $1 \mu \mathrm{l}$ of $25 \mathrm{mM} \mathrm{MgCl} 2,0.25 \mu \mathrm{l}$ of $10 \mathrm{mM} \mathrm{dNTP}$ mix, $1 \mu \mathrm{l}$ of $2 \mu \mathrm{M}$ each reverse and forward primer, and $0.75 \mu \mathrm{l}$ of Taq polymerase (5 units/ $\mu \mathrm{l}$ ). PCR mixtures with $2 \mu \mathrm{l}$ of sterile distilled water without DNA template or with a combination of primer solutions and sterile water were used as negative controls. Each PCR was carried out in a PTC-100 Peltier Thermal Cycler (MJ Research, Inc.) programmed for $10 \mathrm{~min}$ at $95^{\circ} \mathrm{C}$ for initial denaturation, $1 \mathrm{~min}$ at $97^{\circ} \mathrm{C}$, and $7 \mathrm{~min}$ at $95^{\circ} \mathrm{C}$; followed by 45 cycles consisting of $1 \mathrm{~min}$ at $94^{\circ} \mathrm{C}, 1 \mathrm{~min}$ at $55^{\circ} \mathrm{C}$, and $2 \mathrm{~min}$ at $72^{\circ} \mathrm{C}$; completed by a final 10 -min extension at $72^{\circ} \mathrm{C}$. Each PCR was run twice to confirm the result. The amplified PCR products were separated in $6 \%$ nondenaturing polyacrylamide gels in $0.5 \times$ TBE buffer (0.09 M Tris-borate and 0.002 M EDTA) as described previously (41). Each gel was pre-run at $350 \mathrm{~V}$ for $1.5 \mathrm{~h}$ by adding $20 \mu \mathrm{l}$ of ethidium bromide $(10 \mathrm{mg} / \mathrm{ml})$ to the lower reservoirs. After prestaining the gel, $3 \mu \mathrm{l}$ of $2 \times$ loading dye was added to the $10 \mu \mathrm{l}$ of amplified PCR product and loaded into each well. The gel was run at $350 \mathrm{~V}$ for $1.5 \mathrm{~h}$ and photographed in a Fluorochem 2200 Image system (Alpha Innotech Corp.). A 100-bp DNA ladder (Invitrogen Corporation) was used as a size marker. Alleles with the DNA band having the same size were considered to be identical for each SSR locus.

Data analysis. For 17 SSR primer sets, polymorphic DNA bands were scored manually with reference to a 100-bp ladder (Promega Corp.) for all 330 isolates of M. graminicola. Only loci that had alleles of 100 to $500 \mathrm{bp}$ in size and were repeatable and polymorphic were included for data analysis. The sizes of alleles at each of the 17 SSR loci for all isolates were recorded in the GenAlex 6 (36) format. Multilocus haplotypes (MLHTs) were constructed for each isolate by compiling the alleles at all loci.

TABLE 1. Summary information for 330 isolates of Mycosphaerella graminicola sampled from 11 populations in four wheat-growing states of the United States

\begin{tabular}{|c|c|c|c|c|c|c|}
\hline Population & State & Region & Location & Year & Sample size & Wheat type \\
\hline CA & California & Pacific & Colusa County & 2004 & 66 & $\mathrm{~S}(\mathrm{FW}) \mathrm{W}$ \\
\hline IN1 & Indiana & Midwest & Tippecanoe County & 2009 & 35 & SRWW \\
\hline IN2 & Indiana & Midwest & Tippecanoe County & 2009 & 43 & SRWW \\
\hline KS1 & Kansas & Midwest & Multiple & 2003 & 26 & HRWW \\
\hline $\mathrm{KS} 2$ & Kansas & Midwest & Multiple ${ }^{b}$ & 2003 & 15 & HRWW \\
\hline KS3 & Kansas & Midwest & Multiple ${ }^{b}$ & 2003 & 22 & HRWW \\
\hline KS4 & Kansas & Midwest & Ellis County & 2003 & 18 & HRWW \\
\hline KS5 & Kansas & Midwest & Cloud County & 2003 & 20 & HRWW \\
\hline KS6 & Kansas & Midwest & Marion County & 2003 & 20 & HRWW \\
\hline ND1 & North Dakota & North Central & Cavalier County & 2004 & 24 & HRSW \\
\hline ND2 & North Dakota & North Central & Multiple & 1995 & 41 & HRSW \\
\hline
\end{tabular}

a $\mathrm{S}(\mathrm{FW}) \mathrm{W}=$ spring (facultative winter) wheat, SRWW = soft red winter wheat, HRWW = hard red winter wheat, and HRSW = hard red spring wheat.

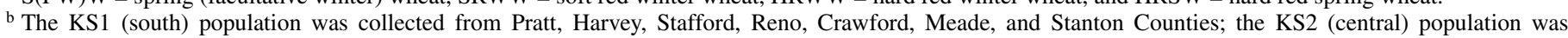
collected from Dickinson, Barton, Ellis, Rush, and Marion Counties; and the KS3 (north) population was collected from Cloud, Mitchell, Rooks, Clay, Jewell, Osborne, Pottawatomie, and Riley Counties.

c Collected from near Langdon (Cavalier County), Minot (Ward County), and Harvey (Wells County). 
Isolates with the same MLHT were considered clones. Clonecorrected data were used for all analyses. POPGENE version 1.32 was used to estimate the total number of alleles and allele frequencies at each SSR locus, gene diversity $(H)$, and Nei's unbiased genetic identity $(I)$ as described previously $(2,46)$. Nei's unbiased $H$ (35) was used to estimate the genetic diversity in the total population $\left(H_{T}\right)$ and within each subpopulation $\left(H_{S}\right)$. The genetic structure of the populations was analyzed by calculating the total gene diversity $\left(H_{T}\right)$ of polymorphic loci and mean gene diversity for each SSR locus within populations $\left(H_{S}\right)$ using the program POPGENE version 1.32 as described by Nei (34). Jost's genetic differentiation, $D(20)$, and $G_{S T}^{\prime \prime}$, a corrected standardized fixation index (30), were calculated as independent measures of differentiation between populations using GenoDive Beta version 2.0 (31). Genotypic diversity was calculated according to the method of Stoddart and Taylor (43), normalized by the maximum possible diversity given the allelic variability within the samples

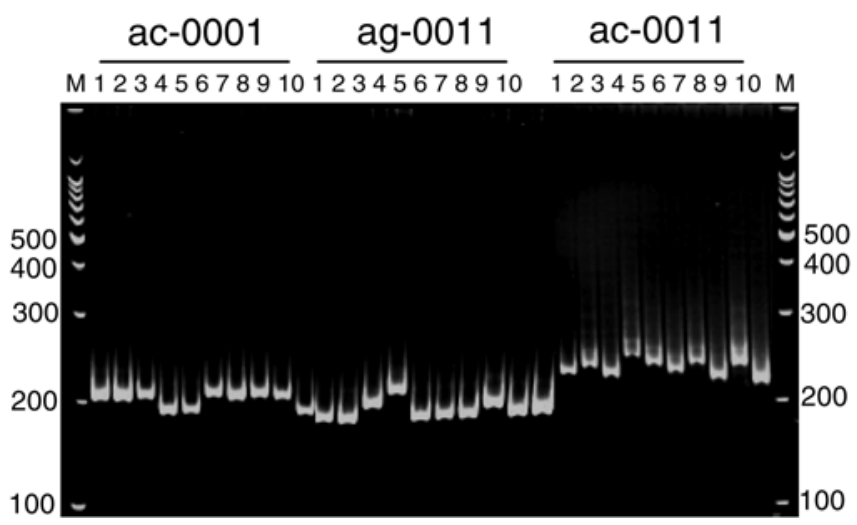

Fig. 1. Amplification profiles from 10 representative isolates of Mycosphaerella graminicola. Lane $1=$ CA36 (California), lane $2=$ CA31 (California), lane $3=$ CA23 (California), lane $4=\mathrm{CA} 15$ (California), lane $5=\mathrm{CA} 7$ (California), lane 6 = FNMP3 (Kansas), lane $7=$ FNMP4 (Kansas), lane $8=$ FNMP5 (Kansas), lane $9=$ FNMP6 (Kansas), and lane 10= FNMP10 (Kansas) at the microsatellite loci ac-0001, ag-0011, and ac-0011. Amplified products were separated by electrophoresis in a $6 \%$ polyacrylamide gel. Lanes 1 and 32 contain a 100-bp DNA size ladder. as suggested by Grunwald et al. (18). In each population, the maximum possible number of genotypes detectable over the 17 SSR loci was >56 million; therefore, the genotypic diversity values were normalized by the sample size. The clonal fraction was measured as $1-$ [(number of different genotypes)/total number of isolates)] (49). The selective neutrality of loci was examined with the Ewens-Watterson test in POPGENE version 1.32 (46).

Multilocus linkage disequilibrium can be assessed using the index of association (i.e., $I_{\mathrm{A}}$ or $r$ BarD). The $r$ BarD is an alternative measure of the index of association and is less sensitive to number of loci when compared with $I_{\mathrm{A}}(3)$. The $r$ BarD values were estimated with the MULTILOCUS program version 1.3 (3) and the values ranged from 0 (i.e., panmixia) to 1 (i.e., absolute linkage disequilibrium). Analysis of molecular variance (AMOVA) is a method that partitions genetic variation within and among populations (13). Arlequin 3.1 software $(12,13)$ was used to estimate AMOVA. Variance components and $F_{S T}$ values were tested by 1,023 permutations of haplotypes among populations to determine levels of significance at $P \leq 0.001$ (12). The genetic variation within and among spring and winter wheat populations along with the two California and North Dakota populations from spring wheat and Indiana and Kansas populations from winter wheat were also determined by AMOVA.

The frequencies of the mating-type alleles within each population were calculated using clone-corrected data. The $\chi^{2}$ test was performed to evaluate the null hypothesis of a $1: 1$ ratio of the two mating types within each population. The similarities of mating type frequencies among sampling units were evaluated using a contingency $\chi^{2}$ test as formulated by Everitt (11).

\section{RESULTS}

Genetic diversity within populations. The number of alleles over all 17 SSR loci averaged 2.94 and their sizes were 190 to 250 bp (Fig. 1). A total of 50 alleles was scored in the 11 populations. The Ewens-Watterson test for neutrality showed all of the polymorphic loci to be selectively neutral (data not shown). Among the 330 isolates analyzed, 306 distinct haplotypes were detected. Six isolates with identical haplotypes were found in the

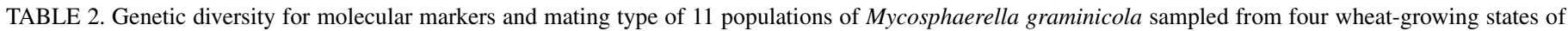
the United States

\begin{tabular}{|c|c|c|c|c|c|c|c|c|}
\hline \multirow[b]{2}{*}{ Population } & \multirow[b]{2}{*}{ Sample size ${ }^{a}$} & \multirow[b]{2}{*}{ Clonal fraction ${ }^{b}$} & \multirow[b]{2}{*}{$\hat{G} / g_{\max }{ }^{\mathrm{c}}$} & \multirow[b]{2}{*}{$H^{\mathrm{d}}$} & \multirow[b]{2}{*}{$r B a r D^{\mathrm{e}}$} & \multicolumn{3}{|c|}{ Mating type } \\
\hline & & & & & & Ratio $^{f}$ & $\chi^{2}$ & $P^{\mathrm{g}}$ \\
\hline $\mathrm{CA}$ & 61 & 0.08 & 61 & 0.44 & $0.006^{*}$ & $42: 19$ & 8.670 & 0.0032 \\
\hline IN1 & 35 & 0.00 & 35 & 0.52 & $0.018 * *$ & $20: 15$ & 0.714 & 0.3980 \\
\hline IN2 & 43 & 0.00 & 43 & 0.50 & 0.004 & $21: 22$ & 0.023 & 0.8788 \\
\hline KS1 & 21 & 0.19 & 21 & 0.39 & $0.021 * *$ & $11: 10$ & 0.048 & 0.8273 \\
\hline $\mathrm{KS} 2$ & 15 & 0.00 & 15 & 0.38 & $0.019 *$ & $7: 8$ & 0.067 & 0.7963 \\
\hline KS3 & 18 & 0.18 & 18 & 0.42 & $0.035 * *$ & $8: 10$ & 0.222 & 0.6374 \\
\hline KS4 & 15 & 0.17 & 15 & 0.32 & 0.001 & $8: 7$ & 0.067 & 0.7963 \\
\hline KS5 & 16 & 0.20 & 16 & 0.31 & 0.002 & $9: 7$ & 0.250 & 0.6171 \\
\hline KS6 & 17 & 0.15 & 17 & 0.32 & 0.014 & $9: 8$ & 0.059 & 0.8084 \\
\hline ND1 & 24 & 0.00 & 24 & 0.54 & 0.005 & $14: 10$ & 0.667 & 0.4142 \\
\hline ND2 & 41 & 0.00 & 41 & 0.56 & 0.000 & $22: 19$ & 0.220 & 0.6394 \\
\hline Total & 306 & $\ldots$ & $\ldots$ & $\ldots$ & $\ldots$ & $171: 135$ & 4.235 & 0.0396 \\
\hline
\end{tabular}

a Clone-corrected sample size.

${ }^{\mathrm{b}}$ Estimated as $1-[($ number of different genotypes)/(total number of isolates) $]$ (49).

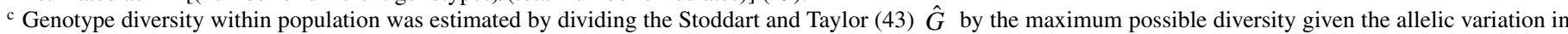
each sample and the sample size as suggested by Grunwald et al. (18). In this case, with 17 loci and two to five alleles per locus, the maximum detectable genotypes is over 56 million; therefore, the maximum $\hat{G}$ in each sample will be equal to the sample size because it is always smaller than the maximum number of detectable genotypes.

d Gene diversity $(H)(34,35)$ within populations was calculated based on clone-corrected data at 17 microsatellite loci $(17)$.

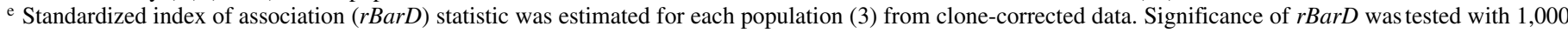
randomizations of the data by comparing the observed value with that expected under the null hypothesis of $r B a r D=0$. The null hypothesis of multilocus linkage equilibrium was rejected if $P \leq 0.001$ or 0.05 ; ** and * indicate significant at $P \leq 0.001$ and 0.05 , respectively.

f MAT-1-1:MAT1-2. Only the California and total samples deviated significantly from the 1:1 ratio expected, assuming equal frequencies of both mating types.

g Probability that the $\chi^{2}$ differs from an expected ratio of $1: 1$ with 1 degree of freedom (11). 
CA population, six in $\mathrm{KS} 1$, five in $\mathrm{KS} 3$, four in $\mathrm{KS} 4$, five in $\mathrm{KS} 5$, and four from KS6. Therefore, 24 isolates appeared to be clones and were excluded from most other analyses. This left all isolates from North Dakota and Indiana, 61/66 isolates from California, and $102 / 121$ isolates from Kansas with unique haplotypes. Estimates of $H$ ranged from 0.31 to 0.56 (Table 2). The KS5 population had the lowest $H$ and the ND2 population the highest. In general, $H$ estimates were high in all 11 populations (Table 2).

Gametic disequilibrium. The $r B a r D$ values for the KS2 and CA populations differed significantly from zero $(P \leq 0.05)$, while those for the IN1, KS1, and KS3 populations were highly significant $(P \leq 0.01)$. The remaining six populations showed no evidence of gametic disequilibrium (Table 2).

Distribution of mating-type alleles within the populations and genotypic diversity. As expected, a single amplicon matching either the MAT1-1 or MAT1-2 allele was detected in each isolate (Fig. 2). Among the 306 isolates analyzed from the 11 populations, 171 were MATl-1 and 135 were MATI-2. The frequency of both mating types deviated significantly from a 1:1 ratio for the CA population but not for any of the others (Table 2). The clonal fractions were low and genotypic diversities were very near the maximum possible values in all populations analyzed (Table 2).

Genetic identity $(I)$ and population differentiation $\left(G{ }^{\prime \prime}{ }_{S T}\right)$ between populations. Identity $(I)$ values calculated between all possible pairwise comparisons among the 11 populations were 0.58 to 0.98 (Table 3 ). The greatest $I$ values were between the

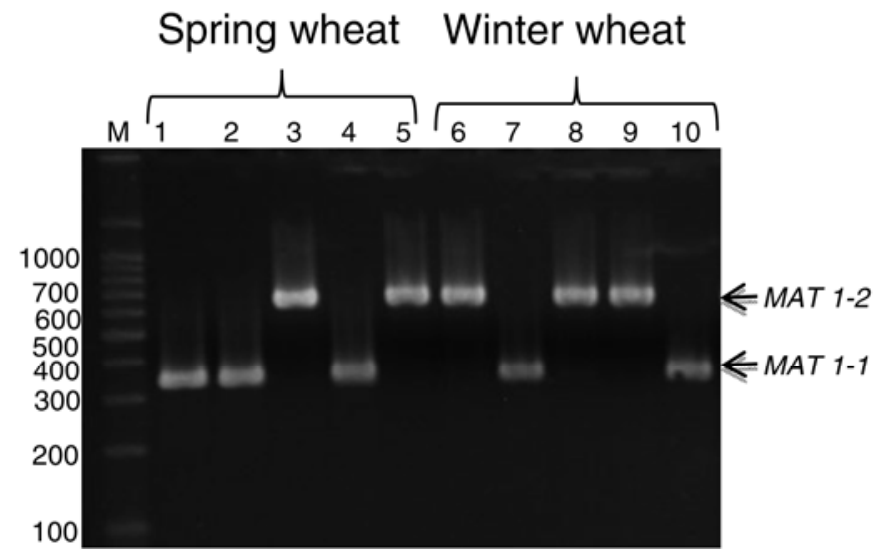

Fig. 2. Ethidium-bromide-stained agarose gel (2\%, run at $120 \mathrm{~W}$ for $1.5 \mathrm{~h}$ ) showing multiplex polymerase chain reaction products with mating-type primer pairs $M A T 1-1 F / R$ and $M A T 1-2 F / R$ in 10 representative isolates of Mycosphaerella graminicola. Lane $1=$ CA36 (California), lane $2=$ CA31 (California), lane 3 = CA23 (California), lane $4=$ CA15 (California), lane $5=$ CA7 (California), lane $6=$ FNMP3 (Kansas), lane $7=$ FNMP4 (Kansas), lane 8 = FNMP5 (Kansas), lane $9=$ FNMP6 (Kansas), and lane $10=$ FNMP10 (Kansas). Lane 1 contains a 100-bp DNA size ladder.
$\mathrm{KS} 1$ and KS2 and the KS1 and KS3 populations. The lowest I values were between IN1 and Kansas populations KS2, KS5, and KS6.

The $G_{S T}^{\prime \prime}$ values for pairwise comparisons between the 11 populations were 0.000 to 0.621 (Table 3 ). The highest $G^{\prime \prime}{ }_{S T}$ was observed between populations IN1 and KS6 (0.621). The lowest $G^{\prime \prime}{ }_{S T}$ values were observed between the Kansas populations KS1, $\mathrm{KS} 2$, and KS3. None of the genetic differentiation values in pairwise comparisons between these three populations was statistically significant. Levels of genetic differentiation between all other population pairs were significantly different either at $P \leq$ 0.001 or $P \leq 0.05$ (Table 3 ). Other measures of genetic differentiation between populations, including $G_{S T}$ and Jost's $D$ that also were calculated by GenoDive (data not shown) (31), showed the same pattern and had the same levels of significance.

Genetic diversity contributed by each SSR locus across the four regional populations varied substantially (Table 4). Each locus was polymorphic in every location but loci gca-0008 and tcc0009 were much less variable in populations representing the California and Kansas environments than in those from the Indiana or North Dakota environments. Mean gene diversity values in the regional populations ranged from 0.41 in Kansas to 0.58 in North Dakota (Table 4).

There was some variability in the amount of genetic diversity detected by each SSR locus (Table 5). SSR loci $a c$-0006 and $a g$ 0003 had the highest $H_{T}$ and $H_{S}$ values within the total sample and regional subpopulations; the lowest values occurred at locus tcc0009 (Table 5). SSR locus gca-0008 had the highest $G^{\prime \prime}{ }_{S T}(0.591)$ among the four regional populations (Table 5). Conversely, SSR locus ag-0006 yielded the lowest $G^{\prime \prime}{ }_{S T}(0.019)$ among the regional populations (Table 5).

AMOVA revealed a small $(1.2 \%)$ but significant $(P<0.000)$ level of genetic differentiation between the combined populations from spring versus winter wheat (Table 6). However, the vast majority of the genetic variation $(>98 \%)$ occurred within these populations (Table 6). Significant genetic differentiation $\left(F_{S T}=\right.$ $0.176, P \leq 0.000)$ also occurred between populations from the spring wheat environments in California versus North Dakota and between populations from winter wheat cultivars in Indiana compared with Kansas $\left(F_{S T}=0.281, P \leq 0.000\right)$. Even in those comparisons, most of the genetic variation $(\geq 72 \%)$ occurred within rather than between populations.

\section{DISCUSSION}

These analyses revealed a small but significant level of genetic differentiation between populations of $M$. graminicola from spring versus winter wheat in the major production areas of the United States as measured by AMOVA. Interestingly, levels of differentiation between subpopulations within each region were higher, with $>20 \%$ of the total genetic variation due to differen-

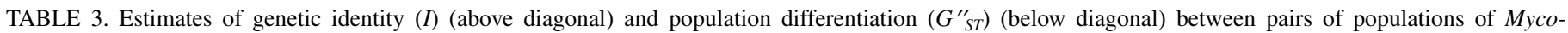
sphaerella graminicola sampled from four wheat-growing states of the United States ${ }^{\mathrm{a}}$

\begin{tabular}{|c|c|c|c|c|c|c|c|c|c|c|c|}
\hline Population & CA & IN1 & IN2 & KS1 & $\mathrm{KS} 2$ & KS3 & KS4 & KS5 & KS6 & ND1 & ND2 \\
\hline $\mathrm{CA}$ & & 0.67 & 0.70 & 0.93 & 0.94 & 0.92 & 0.90 & 0.92 & 0.92 & 0.76 & 0.75 \\
\hline IN1 & $0.486 * *$ & $\ldots$ & 0.95 & 0.62 & 0.59 & 0.64 & 0.61 & 0.59 & 0.58 & 0.94 & 0.91 \\
\hline IN2 & $0.461 * *$ & $0.058^{*}$ & $\ldots$ & 0.65 & 0.64 & 0.68 & 0.61 & 0.62 & 0.61 & 0.90 & 0.89 \\
\hline KS1 & $0.115^{* *}$ & $0.559 * *$ & $0.525 * *$ & $\ldots$ & 0.98 & 0.98 & 0.93 & 0.90 & 0.91 & 0.73 & 0.74 \\
\hline KS2 & $0.179 * *$ & $0.582 * *$ & $0.532 * *$ & $0.00 \mathrm{~ns}$ & $\ldots$ & 0.96 & 0.91 & 0.92 & 0.94 & 0.70 & 0.73 \\
\hline KS3 & $0.142 * *$ & $0.540^{* *}$ & $0.486^{* *}$ & $0.00 \mathrm{~ns}$ & $0.023 \mathrm{~ns}$ & $\ldots$ & 0.93 & 0.89 & 0.90 & 0.75 & 0.74 \\
\hline KS4 & $0.187 * *$ & $0.552 * *$ & $0.565 * *$ & $0.140^{*}$ & $0.152 *$ & $0.165 * *$ & $\ldots$ & 0.91 & 0.92 & 0.74 & 0.71 \\
\hline KS5 & $0.145^{*}$ & $0.587 * *$ & $0.570 * *$ & $0.186^{* *}$ & $0.125 *$ & $0.241 * *$ & $0.157 * *$ & $\ldots$ & 0.96 & 0.68 & 0.70 \\
\hline KS6 & $0.143^{*}$ & $0.621 * *$ & $0.603 * *$ & $0.183 * *$ & $0.097 *$ & $0.207 * *$ & $0.172 * *$ & $0.093 * *$ & $\ldots$ & 0.65 & 0.69 \\
\hline ND1 & $0.372 * *$ & $0.068 *$ & $0.130 * *$ & $0.412 * *$ & $0.442 * *$ & $0.409 * *$ & $0.405 * *$ & $0.493 * *$ & $0.541 * *$ & $\ldots$ & 0.92 \\
\hline ND2 & $0.388 * *$ & $0.117 *$ & $0.157 *$ & $0.409 * *$ & $0.410 * *$ & $0.403 * *$ & $0.445 * *$ & $0.463 * *$ & $0.497 * *$ & $0.087 *$ & $\ldots$ \\
\hline
\end{tabular}

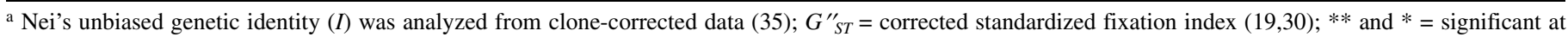
$P \leq 0.001$ and 0.05 , respectively; and $\mathrm{ns}=$ nonsignificant. 
tiation compared with only $1.2 \%$ for populations from spring and winter wheat in total. Almost all of the pairwise comparisons between individual subpopulations showed statistically significant genetic differentiation, regardless of the parameter estimated $\left(G_{S T}\right.$, $G^{\prime \prime}{ }_{S T}$, or Jost's $\left.D\right)$. Taken together, these results indicate that populations of $M$. graminicola in the United States are not part of a single, panmictic population. Instead, local populations are differentiated and may have separate evolutionary trajectories, at least in the short term. Even so, most of the total genetic variation occurred within populations as noted in other locations worldwide, and the level of genetic differentiation was less between the total samples of spring and winter wheat than between subpopulations, indicating a higher degree of homogenization over larger areas. This probably reflects the initial colonization of North America by this fungus during the past several hundred years.

The high levels of genetic diversity within populations and small but significant genetic differentiation between populations are in agreement with analyses of the genetic structure of $M$. graminicola populations in other geographical regions, including the United States $(1,21,26)$. High levels of genetic variability also were found within $M$. graminicola populations from Saskatchewan, western Canada using RAPD markers (37); in Germany and the United States using AFLP markers (21,22,38); in Israel, Switzerland, and parts of the United States using RFLP markers (26); and in France using SSRs (7). Our analysis extended the previous findings to include high levels of genetic diversity in additional regions of the United States for SSR loci located near or within coding regions of genes.

Although we did not estimate migration rates because the populations were not at equilibrium, we can conclude that migration was not sufficient to prevent differentiation over the large geographical areas sampled. This does not contradict previous studies which concluded that migration was very high $(26,51)$. That work reported low values for $G_{S T}$ but did not test whether the differences were significant. However, allele frequencies did differ significantly, indicating that the values for $G_{S T}$, though small, also probably were significantly different. Our analysis reported values for $G^{\prime \prime}{ }_{S T}$ of 0 to 1 ; therefore, the numbers are not directly comparable with those published previously. Values of $G_{S T}$ also were calculated by the GenoDive program (31) and were very similar to those reported previously using different types of markers (data not shown).

There has been much discussion recently about the best possible statistic to use when measuring genetic differentiation between or among populations $(19,20,30,45)$. Most analyses during the past 15 years have used $G_{S T}$, a multi-allelic analog of Wright's $F_{S T}$ that is suitable for haploids as well as diploids (34). A problem with $G_{S T}$ is that it can be difficult to interpret because it

TABLE 5. Summary statistics of Mycosphaerella graminicola at 17 microsatellite loci in the total clone-corrected sample of 306 isolates divided into the four regional populations represented by California, Indiana, Kansas, and North Dakota

\begin{tabular}{lcccc}
\hline Locus & $\begin{array}{c}\text { Number } \\
\text { of alleles }\end{array}$ & $H_{T}^{\mathrm{b}}$ & $H_{S}{ }^{\mathrm{c}}$ & $G^{\prime \prime}{ }^{\prime}{ }^{\mathrm{d}}$ \\
\hline ac-0001 & 4 & 0.616 & 0.495 & 0.372 \\
ac-0002 & 3 & 0.544 & 0.392 & 0.478 \\
ac-0006 & 5 & 0.666 & 0.599 & 0.194 \\
ag-0003 & 3 & 0.665 & 0.605 & 0.133 \\
ag-0006 & 3 & 0.589 & 0.562 & 0.019 \\
ag-0009 & 3 & 0.597 & 0.408 & 0.528 \\
ag-0011 & 3 & 0.585 & 0.461 & 0.371 \\
gca-0004 & 2 & 0.459 & 0.409 & 0.120 \\
gca-0007 & 3 & 0.567 & 0.484 & 0.282 \\
gca-0008 & 3 & 0.501 & 0.258 & 0.591 \\
gca-0010 & 3 & 0.519 & 0.478 & 0.118 \\
gga-0001 & 2 & 0.473 & 0.330 & 0.438 \\
ggc-0001 & 3 & 0.480 & 0.370 & 0.334 \\
tcc-0005 & 2 & 0.505 & 0.455 & 0.113 \\
tcc-0006 & 2 & 0.502 & 0.392 & 0.325 \\
tcc-0008 & 3 & 0.488 & 0.353 & 0.426 \\
tcc-0009 & 3 & 0.439 & 0.303 & 0.429 \\
Mean & 2.94 & 0.541 & 0.433 & 0.332 \\
\hline
\end{tabular}

a Number of alleles in the total sample over the four regional populations.

${ }^{\mathrm{b}} H_{T}=$ gene diversity in the total sample over all four populations.

${ }^{\mathrm{c}} H_{S}=$ mean gene diversity averaged over all four regional populations.

${ }^{\mathrm{d}} G_{S T}^{\prime \prime}=$ corrected standardized fixation index $(19,30)$ among the four populations at each locus.

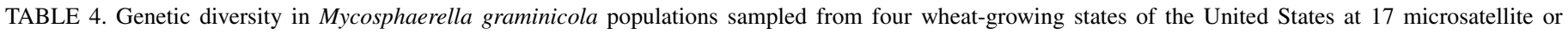
simple-sequence repeat loci ${ }^{\mathrm{a}}$

\begin{tabular}{|c|c|c|c|c|c|c|c|c|c|c|}
\hline \multirow[b]{3}{*}{ Microsatellite ${ }^{\mathrm{b}}$} & \multirow[b]{3}{*}{ Chr. $^{\mathrm{c}}$} & \multirow[b]{3}{*}{ Repeat $^{\mathrm{d}}$} & \multirow[b]{3}{*}{ Length $^{\mathrm{e}}$} & \multirow[b]{3}{*}{ Annotation } & \multicolumn{6}{|c|}{ Gene diversity $^{\mathrm{f}}$} \\
\hline & & & & & \multicolumn{2}{|c|}{ Spring and winter } & \multicolumn{4}{|c|}{ Individual environments } \\
\hline & & & & & SW & WW & CAE & KSE & INE & NDE \\
\hline$a c-0001$ & 7 & 187 & 770 & No match & 0.632 & 0.614 & 0.523 & 0.577 & 0.643 & 0.529 \\
\hline$a c-0002$ & 4 & 190 & 675 & Thioredoxin peroxidase & 0.512 & 0.617 & 0.638 & 0.375 & 0.278 & 0.548 \\
\hline$a c-0006$ & 3 & 182 & 995 & Carbohydrate kinase & 0.681 & 0.642 & 0.604 & 0.625 & 0.668 & 0.640 \\
\hline ag-0003 & 3 & 247 & 2,032 & Hypothetical protein & 0.662 & 0.664 & 0.654 & 0.656 & 0.633 & 0.622 \\
\hline ag-0006 & 1 & 156 & 392 & No match & 0.589 & 0.610 & 0.616 & 0.546 & 0.605 & 0.602 \\
\hline ag-0009 & 13 & 196 & 982 & No match & 0.627 & 0.588 & 0.397 & 0.404 & 0.291 & 0.655 \\
\hline ag-0011 & 3 & 175 & 541 & No match & 0.620 & 0.580 & 0.422 & 0.453 & 0.602 & 0.649 \\
\hline gca-0004 & 1 & 174 & 2,141 & Hypothetical protein & 0.449 & 0.489 & 0.334 & 0.364 & 0.500 & 0.567 \\
\hline gca-0007 & 1 & 166 & 585 & Zinc finger protein & 0.583 & 0.562 & 0.493 & 0.479 & 0.653 & 0.527 \\
\hline gca-0008 & 8 & 153 & 321 & No match & 0.535 & 0.513 & 0.114 & 0.181 & 0.525 & 0.320 \\
\hline gca-0010 & 11 & 179 & 513 & Programmed cell death & 0.507 & 0.585 & 0.500 & 0.443 & 0.582 & 0.603 \\
\hline gga-0001 & 21 & 157 & 355 & No match & 0.476 & 0.489 & 0.493 & 0.308 & 0.416 & 0.490 \\
\hline ggc-0001 & 5 & 227 & 1,322 & RNA binding protein & 0.510 & 0.547 & 0.382 & 0.205 & 0.637 & 0.625 \\
\hline tcc-0005 & 3 & 226 & 562 & High-affinity nickel & 0.471 & 0.550 & 0.382 & 0.459 & 0.484 & 0.639 \\
\hline tcc-0006 & 1 & 170 & 558 & Hypothetical protein & 0.504 & 0.499 & 0.493 & 0.459 & 0.341 & 0.485 \\
\hline tcc-0008 & 7 & 152 & 530 & Hypothetical protein & 0.435 & 0.624 & 0.478 & 0.205 & 0.576 & 0.657 \\
\hline tcc-0009 & 6 & 159 & 483 & No match & 0.465 & 0.493 & 0.030 & 0.179 & 0.593 & 0.632 \\
\hline Mean & $\ldots$ & $\ldots$ & $\ldots$ & $\ldots$ & 0.545 & 0.569 & 0.444 & 0.406 & 0.531 & 0.575 \\
\hline
\end{tabular}

${ }^{\text {a }}$ Both microsatellite loci and putative functions are according to Goodwin et al. (17).

b Microsatellite locus.

c Chromosome (Chr.) of the loci in the genome sequence $(16,17)$.

${ }^{\mathrm{d}}$ Repeat sequence, based on a North America isolate of M. graminicola (17).

e Length in genome sequence.

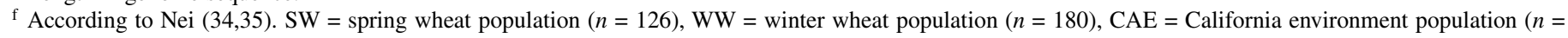

$61)], \mathrm{KSE}=$ Kansas environment population $(n=102), \mathrm{INE}=$ Indiana environment population $(n=78)$, and NDE $=$ North Dakota environment population $(n=65)$. 
can be low even when the absolute differentiation is high; therefore, Hedrick (19) proposed to normalize it by dividing by the maximum possible differentiation given the observed diversity in a sample to yield $G_{S T}^{\prime}$. Variations of this approach include $R_{S T}$ for microsatellite loci with very high mutation rates and $G^{\prime \prime}{ }_{S T}$ to correct for limited sampling of populations (30). Jost (20) pointed out a number of problems with all of these measures and proposed an alternative statistic for genetic differentiation, $D$. However, Jost's $D$ so far has not been widely accepted and Whitlock (45) has argued for retaining $F_{S T}$ or $G_{S T}$ for ease of interpretation and for comparisons with previous work. The SSR loci analyzed in our populations had two to five alleles and, therefore, do not seem to have extremely high mutation rates. The values of $G_{S T}$ were low, indicating a relatively high migration rate, certainly higher than that for mutation. Therefore, we chose to report the pairwise estimates of differentiation with the standardized, corrected measure, $G^{\prime \prime}{ }_{S T}$. Advantages of this statistic are that it is corrected for the relatively small number of populations sampled and ranges between 0 and 1 for easy comparisons among locations (19).

The low clonal fractions with correspondingly high genotypic diversities plus the equal frequencies of the two mating types most likely reflect a high rate of sexual reproduction in $M$. graminicola populations throughout the United States. The only exception was the population from California, which had an excess of the MAT-1-1 allele even though genotypic diversity was very high. Ascospores are believed to play an important role for initiating and maintaining epidemics of STB in wheat fields $(9,23,44)$ and a positive correlation has been found between the rate of sexual recombination and the level of genetic variation in natural populations $(8,25)$. Consistent with the ascospore hypothesis, equal frequencies of both mating types and high genotypic diversity seem to be the norm for $M$. graminicola populations worldwide (47), including the United States. The reasons for the deviation from a 1:1 ratio of the mating types in the California population are not known. One possible explanation for such a deviation could be if the sample size was small, giving an artifact. For example, Waalwijk et al. (44) found only the MAT1-1 mating type in one population from Syria but a slight excess of the MAT1-2 mating type in a second population and concluded that the small sizes of 10 and 9 individuals, respectively, could be the cause of this variation. However, in our case, the sample size from California of 61 individuals after clone correction is large enough to minimize sampling artifacts; therefore, other explanations are needed.

A recent analysis showed that MAT1-1 isolates, on average, were more pathogenic compared with MAT1-2 isolates in four of five samples analyzed (52). Although the difference was small, it was statistically significant. In our California population and the overall sample, the MAT1-1 idiomorph was always the most frequent, consistent with populations throughout the world (47). Therefore, selection favoring the MAT1-1 idiomorph may be the most likely explanation for its significantly increased frequency in our California and overall samples, although other explanations, including type I statistical errors (false rejection of the null hypothesis), are possible $(42,47)$. Clearly, additional sampling from California is needed to confirm this result and to determine its cause.

An organism with wider dispersal ability is expected to show greater genetic uniformity across local populations compared with one with lower dispersal ability $(27,48)$. In this study, we hypothesized that $M$. graminicola populations sampled from geographically separated production regions of the United States growing spring or winter wheat cultivars of different market classes would be the most likely to show genetic differentiation, because they have experienced different climatic conditions, cropping systems, agronomical practices, and separate breeding programs utilizing different sources of resistance. Our results were consistent with the null hypothesis of genetic differentiation. Even though the magnitude of the differentiation was small, it was significant statistically; therefore, is likely to be real. Thus, the different wheat cultivars, environmental conditions, and agronomical practices in California, Indiana, Kansas, and North Dakota are enough to create genetic differentiation among populations of $M$. graminicola.

Another difference between our results and those reported in previous publications was the finding of significant gametic disequilibrium. Kabbage et al. (21) used AFLP markers and found no evidence of gametic disequilibrium in the $M$. graminicola populations from Kansas and California. Significant gametic disequilibrium has not been described in most of the previous studies using RFLP or AFLP markers $(5,26,38)$. A possible cause of gametic disequilibrium is linkage. To test whether this could have affected our results, we determined the physical location of each SSR locus based on the genomic sequence of $M$. graminicola (Table 4) (16) and also looked at previously calculated genetic linkages (17). Among the 17 microsatellite loci analyzed in this study, 4 each were positioned on chromosomes 1 and 3 and 2 were on chromosome 7 . The remaining seven loci were on different chromosomes and, therefore, could not have been affected by linkage.

The two SSR loci on chromosome 7 are far enough apart that they were not linked genetically (17), while those on chromosome 3 were unlinked except for loci ag-0003 and tcc-0005, which were separated by 19 centimorgans (cM). This level of linkage is not enough to cause the gametic disequilibrium seen in our

TABLE 6. Analysis of molecular variance (AMOVA) testing for genetic differentiation between spring wheat and winter wheat populations of Mycosphaerella graminicola sampled from four wheat-growing areas of the United States

\begin{tabular}{|c|c|c|c|c|}
\hline AMOVA $^{\mathrm{a}}$ & df & Variation $(\%)$ & $F_{S T}^{\mathrm{b}}$ & $P$ \\
\hline Among four populations within regions & 3 & 18 & & \\
\hline Within four populations & 302 & 82 & 0.180 & 0.000 \\
\hline \multicolumn{5}{|l|}{ Spring wheat vs. winter wheat populations } \\
\hline Within populations & 304 & 98.2 & $\ldots$ & $\ldots$ \\
\hline \multicolumn{5}{|l|}{ Spring wheat populations } \\
\hline Among California vs. North Dakota population & 1 & 17.7 & 0.176 & 0.000 \\
\hline Within California vs. North Dakota population & 124 & 82.3 & $\ldots$ & $\ldots$ \\
\hline Within Indiana vs. Kansas population & 178 & 71.9 & $\ldots$ & $\ldots$ \\
\hline
\end{tabular}

${ }^{a}$ Genetic variation was partitioned within and among populations at several hierarchical levels and groupings of populations within the four environments represented by populations from California (facultative spring wheat), North Dakota (spring wheat), Indiana (soft red winter wheat), and Kansas (hard red winter wheat). Genetic differentiation also was compared between spring wheat populations from California vs. North Dakota, and winter wheat populations from Indiana vs. Kansas.

${ }^{\mathrm{b}} F_{S T}=$ fixation index; significance was determined by 1,023 random permutations. Clone-corrected data were used for AMOVA. 
analysis. All four microsatellite loci on chromosome 1 were linked, two of them very tightly. Locus ag-0006 mapped $33 \mathrm{cM}$ from gca-0007, which also would not explain our observed gametic disequilibrium. However, locus gca-0007 was only $1 \mathrm{cM}$ from gca-0004, which was $9 \mathrm{cM}$ from tcc-0006 (17). The tight linkages among these three loci possibly could explain our results. To test this hypothesis, we repeated the analysis of gametic disequilibrium after removal of the data for gca-0004, which had no effect on the significance of the results. Removal of the data for both $\mathrm{gca}$-0004 and gca-0007 caused the disequilibrium in population KS2 to become nonsignificant; however, the significance of the disequilibrium remained unchanged for the other populations. Interestingly, removal of tcc-0005 in addition to $\mathrm{gca}$ 0004 and gca-0007 again gave significant disequilibrium in KS2 and did not affect the significance of the disequilibrium in the other four populations. With those three SSR loci removed, all 14 loci remaining in the analysis were unlinked. Thus, physical linkage of the microsatellite loci cannot explain the gametic disequilibrium observed in populations CA, IN1, KS1, and KS3, although it may have been the cause for some of that in population KS2.

Another possible cause of gametic disequilibrium is physical admixture of samples that differ in allele frequencies (32). Kansas populations KS1 and KS3 contained pooled populations of isolates and this could cause disequilibrium if allele frequencies varied among the counties sampled. Gene diversity values among the populations are also different for individual loci, which suggest that they may be subject to selection. Therefore, selection for particular combinations of alleles at the genes marked by the SSR loci may be the most likely explanation for the observed disequilibria seen in the CA and IN1 samples. Additional analyses of the loci giving the significant disequilibrium values are needed to test the selection hypothesis.

This study confirms that the geographical and ecological separation among the regional populations is enough to prevent complete genetic homogenization by gene flow through the arrival of new alleles, resulting in genetic differentiation among populations. However, the forces causing the differentiation are not known. Genetic drift is unlikely because $M$. graminicola populations seem to have very large effective sizes. Selection at one or more of the loci marked by the SSR primers or at closely linked loci could explain the genetic differentiation between populations as well as the significant gametic disequilibrium but is not consistent with the results of the neutrality tests. The relatively low differentiation values indicate that some level of migration occurs, even if it could not be tested using the usual indirect measures. In this study, some haplotypes of $M$. graminicola were shared among the populations. Whether these were clones that migrated between populations or were simply individuals that had the same multilocus haplotypes by chance is not known.

The ability of a pathogen to disseminate over long distances has a direct impact on disease-management strategies in agricultural ecosystems (6). McDonald and Linde (27) proposed that pathogens with high gene or genotype flow pose a more severe threat compared with pathogens with low gene or genotype flow. This study confirms that M. graminicola populations in North America can recombine frequently to create new genotypes and can increase their gene diversity through migration, with high potential for short-distance gene flow. The high genotypic diversity among highly variable populations of $M$. graminicola in the four sampled wheat production environments of the United States suggest that major resistance genes may break down quickly and should be deployed cautiously.

\section{ACKNOWLEDGMENTS}

This work was supported by the Agricultural Experiment Stations of Kansas State University, Purdue University, and North Dakota State
University, and by United States Department of Agriculture-Agricultural Research Service CRIS project 3602-22000-015-00D. We thank L. Jackson, University of California at Davis, for providing infected leaf samples.

\section{LITERATURE CITED}

1. Abrinbana, M., Mozafiri, J., Shams-bakhsh, M., and Mehrabi, R. 2010. Genetic structure of Mycosphaerella graminicola populations in Iran. Plant Pathol. 59:829-838.

2. Adhikari, T. B., Ali, S., Burlakoti, R. R., Singh, P. K., Mergoum, M., and Goodwin, S. B. 2008. Genetic structure of Phaeosphaeria nodorum populations in the North-Central and Midwestern United States. Phytopathology 98:101-107.

3. Agapow, P. M., and Burt, A. 2001. Indices of multilocus linkage disequilibrium. Mol. Ecol. Notes 1:101-102.

4. Bearchell, S. J., Fraaije, B. A., Shaw, M. W., and Fitt, B. D. L. 2005. Wheat archive links long-term fungal pathogen population dynamics to air pollution. Proc. Natl. Acad. Sci. USA 102:5438-5442.

5. Boeger, J. M, Chen, R. S., and McDonald, B. A. 1993. Gene flow between geographic populations of Mycosphaerella graminicola (anamorph Septoria tritici) detected with restriction fragment length polymorphism markers. Phytopathology 83:1148-1154.

6. Brown, J. K. M., and Hovmøller, M. S. 2002. Aerial dispersal of pathogens on the global and continental scales and its impact on plant disease. Science 297:537-541.

7. Chartouni, L. E., Tisserant, B., Siah, A., Duyme, F., Leducq, J. B., Deweer, C., Roisin, C. F., Sanssené, J., Durand, R., Halama, P., and Reignault, P. P. 2011. Genetic diversity and population structure in French populations of Mycosphaerella graminicola. Mycologia. Online publication. doi:10.3852/10-184.

8. Chen, R. S., and McDonald, B. A. 1996. Sexual reproduction plays a major role in the genetic structure of populations of the fungus Mycosphaerella graminicola. Genetics 142:1119-1127.

9. Cowger, C., McDonald, B. A., and Mundt, C. C. 2002. Frequency of sexual reproduction by Mycosphaerella graminicola on partially resistant wheat cultivars. Phytopathology 92:1175-1181.

10. Eriksen, L., Shaw, M. W., and Østergård, H. 2001. A model of the effect of pseudothecia on genetic recombination and epidemic development in populations of Mycosphaerella graminicola. Phytopathology 91:240-248.

11. Everitt, B. S. 1977. The Analysis of Contingency Tables. Wiley, New York.

12. Excoffier, L., Laval, G., and Schneider, S. 2005. Arlequin (version 3.0): An integrated software package for population genetics data analysis. Evol. Bioinf. 1:47-50.

13. Excoffier, L., Smouse, P. E., and Quattro, J. M. 1992. Analysis of molecular variance inferred from metric distances among DNA haplotypes: Application to human mitochondrial DNA restriction data. Genetics 131:479-491.

14. Eyal, Z. 1981. Integrated control of Septoria diseases of wheat. Plant Dis. 65:763-768.

15. Eyal, Z., Scharen, A. L., Huffman, M. D., and Prescott, J. M. 1985. Global insights into virulence frequencies of Mycosphaerella graminicola. Phytopathology 75:1456-1462.

16. Goodwin, S. B., Ben M'Barek, S., Dhillon, B., Wittenberg, A. H. J., Crane, C. F., Hane, J. K., Foster, A. J., Van der Lee, T. A. J., Grimwood, J., Aerts, A., Antoniw, J., Bailey, A., Bluhm, B., Bowler, J., Bristow, J., van der Burgt, A., Canto-Canche, B., Churchill, A. C. L., Conde-Ferràez, L., Cools, H. J., Coutinho, P. M., Csukai, M., Dehal, P., De Wit, P., Donzelli, B., van de Geest, H. C., van Ham, R. C. H. J., HammondKosack, K. E., Henrissat, B. Kilian, A., Kobayashi, A. K., Koopmann, E., Kourmpetis, Y., Kuzniar, A., Lindquist, E., Lombard, V., Maliepaard, C., Martins, N., Mehrabi, R., Nap, J. P. H., Ponomarenko, A., Rudd, J. J., Salamov, A., Schmutz, J., Schouten, H. J., Shapiro, H., Stergiopoulos, I., Torriani, S. F. F., Tu, H., de Vries, R. P., Waalwijk, C., Ware, S. B., Wiebenga, A., Zwiers, L.-H., Oliver, R. P., Grigoriev, I. V., and Kema, G. H. J. 2011. Finished genome of the fungal wheat pathogen Mycosphaerella graminicola reveals dispensome structure, chromosome plasticity and stealth pathogenesis. PLoS Genet. 7(6):e1002070. doi:10.1371/ journal.pgen.1002070.

17. Goodwin, S. B., van der Lee, T. A. J., Cavaletto, J. R., Hekkert, B. T. L., Crane, C. F., and Kema, G. H. J. 2007. Identification and genetic mapping of highly polymorphic microsatellite loci from and EST database of the Septoria tritici blotch pathogen Mycosphaerella graminicola. Fungal Genet. Biol. 44:398-414.

18. Grünwald, N. J., Goodwin, S. B., Milgroom, M. G., and Fry, W. E. 2003. Analysis of genotypic diversity data for populations of microorganisms. Phytopathology 93:738-746.

19. Hedrick, P. 2005. A standardized genetic differentiation measure. 
Evolution 59:1633-1638.

20. Jost, L. 2008. $G_{S T}$ and its relatives do not measure differentiation. Mol. Ecol. 17:4015-4026.

21. Kabbage, M., Leslie, J. F., Hulbert, S. H., and Bockus, W. W. 2009. Comparison of natural populations of Mycosphaerella graminicola from single fields in Kansas and California. Physiol. Mol. Plant Pathol. 74:5559 .

22. Kabbage, M., Leslie, J. F., Zeller, K. A., Hulbert, S. H., and Bockus, W. W. 2008. Genetic diversity of Mycosphaerella graminicola, the causal agent of Septoria tritici blotch, in Kansas winter wheat. J. Agric. Food Environ. Sci. 2:1-9.

23. Kema, G. H. J., Verstappen, E. C. P., Todorova, M., and Waalwijk, C. 1996. Successful crosses and molecular trend and progeny analyses demonstrate heterothallism in Mycosphaerella graminicola. Curr. Genet. 30:251-258.

24. Kerényi, Z., Zeller, K. A., Hornok, L., and Leslie, J. F. 1999. Molecular standardization of mating type terminology in the Gibberella fujikuroi species complex. Appl. Environ. Microbiol. 65:4071-4076.

25. Kraft, T., Sall T., Magnusson-Rading, I., Nilsson, N. O., and Hallden, C. 1998. Positive correlation between recombination rates and levels of genetic variation in natural populations of sea beet (Beta vulgaris subsp. maritima). Genetics 150:1239-1244.

26. Linde, C., Zhan, J., and McDonald, B. A. 2002. Population structure of Mycosphaerella graminicola: from lesions to continents. Phytopathology 92:946-955.

27. McDonald, B. A., and Linde, C. 2002. Pathogen population genetics, evolutionary potential, and durable resistance. Annu. Rev. Phytopathol. 40:349-379.

28. McDonald, B. A., and Martinez, J. P. 1990. DNA restriction fragment length polymorphisms among Mycosphaerella graminicola (anamorph Septoria tritici) isolates collected from a single wheat field. Phytopathology 80:1368-1373.

29. McDonald, B. A., and McDermott, J. M. 1993. The population genetics of plant pathogenic fungi. BioScience 43:311-319.

30. Meirmans, P. G., and Hedrick, P. W. 2011. Assessing population structure: $F_{S T}$ and related measures. Mol. Ecol. Resour. 11:5-18.

31. Meirmans, P. G., and van Tienderen, P. H. 2004. GENOTYPE and GENODIVE: Two programs for the analysis of genetic diversity of asexual organisms. Mol. Ecol. Notes 4:792-794.

32. Milgroom, M. G. 1996. Recombination and the multilocus structure of fungal populations. Annu. Rev. Phytopathol. 34:457-477.

33. Murray, M. G., and Thompson, W. F. 1980. Rapid isolation of high molecular weight plant DNA. Nucleic Acids Res. 8:4321-4325.

34. Nei, M. 1973. Analysis of gene diversity in subdivided populations. Proc. Natl. Acad. Sci. USA 70:3321-3323.

35. Nei, M. 1978. Estimation of average heterozygosity and genetic distance from a small number of individuals. Genetics 89:583-590.

36. Peakall, R., and Smouse, P. E. 2006. GENALEX 6: Genetic analysis in Excel. Population genetic software for teaching and research. Mol. Ecol. Notes 6:288-295.

37. Razavi, M., and Hughes, G. R. 2004. Molecular variability of Mycosphaerella graminicola as detected by RAPD markers. J. Phytopathol.
152:543-548.

38. Schneider, F., Koch, G., Jung, C., and Verreet, J. A. 2001. Genotypic diversity of the wheat leaf blotch pathogen Mycosphaerella graminicola (anamorph) Septoria tritici in Germany. Eur. J. Plant Pathol. 107:285-290.

39. Selkoe, K. A., and Toonen, R. J. 2006. Microsatellites for ecologists: a practical guide to using and evaluating microsatellite markers. Ecol. Lett. 9:615-629.

40. Shaw, M. W., and Royle, D. J. 1989. Airborne inoculums as a major source of Septoria tritici (Mycosphaerella graminicola) infections in winter wheat crops in the UK. Plant Pathol. 38:35-43.

41. Shi, J., Ward, R., Wang, D., and Lewis, J. 2001. Application of a high throughput, low cost, non-denaturing polyacrylamide gel system for wheat microsatellite mapping. Pages 25-30 in: National Fusarium Head Blight Forum, Erlanger, KY.

42. Sommerhalder, R. J., McDonald, B. A., and Zhan, J. 2006. The frequencies and spatial distribution of mating types in Stagonospora nodorum are consistent with recurring sexual reproduction. Phytopathology 96:234-239.

43. Stoddart, J. A., and Taylor, J. F. 1988. Genotypic diversity: estimation and prediction in samples. Genetics 118:705-711.

44. Waalwijk, C., Mendes, O., Verstappen, E. C. P., de Waard, M. A., and Kema, G. H. J. 2002. Isolation and characterization of the mating type idiomorphs from the wheat Septoria leaf blotch fungus Mycosphaerella graminicola. Fungal Genet. Biol. 35:277-286.

45. Whitlock, M. C. 2011. $G_{\text {ST }}^{\prime}$ and $D$ do not replace $F_{S T}$. Mol. Ecol. 20:1083-1091.

46. Yeh, F. C., Yang, R. C., Boyle, T. B. J., Ye, Z. H., and Mao, J. X. 1997. POPGENE, the User Friendly Shareware for Population Genetic Analysis. Molecular Biology and Biotechnology Center, University of Alberta, Canada.

47. Zhan, J., Kema, G. H. J., Waalwijk, C., and McDonald, B. A. 2002. Distribution of mating type alleles in the wheat pathogen Mycosphaerella graminicola over spatial scales from lesions to continents. Fungal Genet. Biol. 36:128-136.

48. Zhan, J., and McDonald, B. A. 2004. The interaction among evolutionary forces in the pathogenic fungus Mycosphaerella graminicola. Fungal Genet. Biol. 41:590-599.

49. Zhan, J., Mundt, C. C., Hoffer, M. E., and McDonald, B. A. 2002. Local adaptation and effect of host genotype on the evolution of virulence: An experimental test in a plant pathosystem. J. Evol. Biol. 15:634-647.

50. Zhan, J., Mundt, C. C., and McDonald, B. A. 2001. Using RFLPs to assess temporal variation and estimate the number of ascospores that initiate epidemics in field populations of Mycosphaerella graminicola. Phytopathology 91:1011-1017.

51. Zhan, J., Pettway, R. E., and McDonald, B. A. 2003. The global genetic structure of the wheat pathogen Mycosphaerella graminicola is characterized by high nuclear diversity, low mitochondrial diversity, regular recombination, and gene flow. Fungal Genet. Biol. 38:286-297.

52. Zhan, J., Torriani, S. F. F., and McDonald, B. A. 2007. Significant difference in pathogenicity between MAT1-1 and MAT1-2 isolates in the wheat pathogen Mycosphaerella graminicola. Fungal Genet. Biol. 44:339-346. 